\title{
C-reactive Protein Concentration Is Associated With a Higher Risk of Mortality in a Rural Korean Population
}

\author{
Jung Hyun Lee', Hyungseon Yeom², Hyeon Chang Kim², Il Suh², Mi Kyung Kim³, Min-Ho Shin ${ }^{4}$, Dong Hoon Shin ${ }^{5}$, \\ Sang-Baek Koh ${ }^{6,7}$, Song Vogue Ahn ${ }^{6,7}$, Tae-Yong Lee ${ }^{8}$, So Yeon Ryu ${ }^{9}$, Jae-Sok Song ${ }^{10}$, Hong-Soon Choe ${ }^{10}$, \\ Young-Hoon Lee ${ }^{11}$, Bo Youl Choi ${ }^{3}$ \\ ${ }^{1}$ Graduate School of Public Health, Yonsei University, Seoul; '2Department of Preventive Medicine, Yonsei University College of Medicine, Seoul; \\ ${ }^{3}$ Department of Preventive Medicine, Hanyang University College of Medicine, Seoul; ${ }^{4}$ Department of Preventive Medicine, Chonnam National \\ University Medical School, Gwangju; ${ }^{5}$ Department of Preventive Medicine, Keimyung University School of Medicine, Daegu; Department of \\ Preventive Medicine, Yonsei University Wonju College of Medicine, Wonju; ${ }^{7}$ Institute of Genomic Cohort, Yonsei University Wonju College of \\ Medicine, Wonju; ${ }^{8}$ Department of Preventive Medicine, Chungnam National University School of Medicine, Daejeon; ${ }^{9}$ Department of Preventive \\ Medicine, Chosun University Medical School, Gwangju; ${ }^{10}$ Department of Preventive Medicine and Institute of Catholic Kwandong University College \\ of Medicine, Gangneung; ${ }^{11}$ Department of Preventive Medicine and Institute of Wonkwang Medical Science, Wonkwang University School of \\ Medicine, Iksan, Korea
}

Objectives: C-reactive protein (CRP), an inflammatory biomarker, has been widely used as a preclinical marker predictive of morbidity and mortality. Although many studies have reported a positive association between CRP and mortality, uncertainty still remains about this association in various populations, especially in rural Korea.

Methods: A total of 23233 middle-aged participants (8862 men and 14371 women) who were free from cardiovascular disease, cancer, and acute inflammation (defined by a CRP level $\geq 10 \mathrm{mg} / \mathrm{L}$ ) were drawn from 11 rural communities in Korea between 2005 and 2011. Blood CRP concentration was analyzed as a categorical variable (low: 0.0-0.9 mg/L; intermediate: 1.0-3.0 mg/L; high: 3.1-9.9 mg/L) as well as a continuous variable. Each participant's vital status through December 2013 was confirmed by death statistics from the National Statistical Office. Cox proportional hazard models were used to assess the independent association between CRP and mortality after adjusting for other risk factors.

Results: The total quantity of observed person-years was 57975 for men and 95146 for women, and the number of deaths was 649 among men and 367 among women. Compared to the low-CRP group, the adjusted hazard ratio for all-cause mortality of the intermediate group was 1.17 (95\% confidence interval [Cl], 0.98 to 1.40) for men and 1.27 (95\% Cl, 1.01 to 1.61) for women, and the corresponding values for the high-CRP group were 1.98 (95\% Cl, 1.61 to 2.42$)$ for men and 1.41 (95\% Cl, 1.03 to 1.95$)$ for women. Similar trends were found for CRP evaluated as a continuous variable and for cardiovascular mortality.

Conclusions: Higher CRP concentrations were associated with higher mortality in a rural Korean population, and this association was more prominent in men than in women.

Key words: C-reactive protein, Mortality, Cardiovascular diseases, Rural population, Republic of Korea

Received: February 29, 2016 Accepted: August 18, 2016

Corresponding author: Hyeon Chang Kim, MD, PhD

50-1 Yonsei-ro, Seodaemun-gu, Seoul 03722, Korea.

Tel: +82-2-2228-1873, Fax: +82-2-392-8133

E-mail: hckim@yuhs.ac

This is an Open Access article distributed under the terms of the Creative Commons Attribution Non-Commercial License (http://creativecommons.org/licenses/bync/4.0// which permits unrestricted non-commercial use, distribution, and reproduction in any medium, provided the original work is properly cited.

\section{INTRODUCTION}

Chronic inflammation has been considered to be an emerging risk factor for many chronic diseases, such as cancers and cardiovascular disease (CVD) [1-3]. C-reactive protein (CRP) is a widely used inflammatory marker, and reflects both acute and chronic inflammation status. Although many other biomarkers 
indicate inflammation status, such as fibrinogen levels, white cell count, and erythrocyte sedimentation rate, CRP is the only established biomarker that can be used for risk assessment as part of the primary prevention of CVD [4,5]. Several studies have reported associations between CRP and the incidence of vascular and non-vascular disease $[6,7]$, as well as associations between CRP and cause-specific and all-cause mortality [811]. Recently, some articles have suggested that these associations may be affected by the presence of other risk factors for CVD [12-16]. It is not clear whether CRP is directly associated with mortality or is associated with mortality due to the presence of other risk factors, such as hypertension.

In addition, most previous studies addressing associations between CRP and mortality have reported findings from Western populations $[7,12,17]$. Although some studies have been carried out in East Asia, few studies have dealt with rural populations $[6,11,13]$. Differently distributed blood concentrations of CRP have been found in different ethnic groups, and the relationship between mortality and CRP has been found to vary between rural and urban areas due to distinct lifestyle factors [18-20]. The role of CRP in predicting risk for CVD and mortality appears to be different from population to population. To the best of our knowledge, no previous research has assessed the association between CRP and all-cause mortality in a rural Korean population. Thus, we aimed to evaluate the association of CRP with all-cause mortality and cardiovascular mortality in rural regions in Korea. Additionally, we aimed to determine whether the association between CRP and all-cause mortality was modified by the presence of hypertension.

\section{METHODS}

\section{Study Participants}

We used data from the Korean Genome and Epidemiology Study - Cardiovascular Disease Association Study (KoGES_CAVAS). The aims, recruitment criteria, and baseline characteristics of KoGES_CAVAS have been described in more detail elsewhere [21]. In brief, a total of 28338 community dwellers (age $\geq 40$ years) were recruited from 11 rural communities in Korea from 2005 to 2011. In eight communities, the study participants were recruited beginning in 2005, and those in the other three communities were recruited beginning in 2006. The follow-up is ongoing, and in this study, we assessed mortality cases based on data from the National Statistical Office. We excluded 2346 participants with a history of stroke, angina, myo- cardial infarction, or cancer, and then excluded 484 participants due to evidence of acute inflammation (CRP $\geq 10 \mathrm{mg} / \mathrm{L}$ ). Next, we excluded 227 participants whose vital status could not be confirmed, as well as 1604 participants whose CRP concentrations were not measured. Finally, we excluded 442 participants due to missing data in some independent variables, as well as two participants who died in the same month that they were enrolled in the study. Thus, a total of 23233 people (8862 men and 14371 women) were included in the final analysis. All participants provided written informed consent, and the study protocol was approved by the institutional review board of each institution that participated in KoGES_CAVAS.

\section{Data Collection}

Information about demographic factors, socioeconomic status, health behaviors, and disease history were collected using a standardized questionnaire. Educational status was used to represent socioeconomic status, and was defined as elementary school or below, middle school, high school, and university or above. Non-smokers were defined as those who had consumed less than 400 cigarettes over the course of their lifetime [22]. Participants who had consumed 400 or more cigarettes were categorized into two groups: former smokers, who abstained from smoking at the time of the questionnaire, and current smokers, who persisted in smoking. Participants were divided according to their alcohol consumption as never drinkers, former drinkers, and current drinker. Never drinkers were defined as those who had never consumed an alcoholic drink over the course of their lifetime, for physical or other reasons. Former drinkers were defined as participants who abstained from drinking at the time of the questionnaire, while current drinkers were defined as those who persisted in consuming alcohol. Participants were classified in terms of regular exercise based on 'yes' and 'no' answers to the following question. "Do you currently engage in regular exercise strenuous enough to cause you to break into a sweat at least once per week?"

Anthropometric measurements were also obtained using standardized methods. Body mass index (BMI) was calculated as weight $(\mathrm{kg})$ divided by height squared $\left(\mathrm{m}^{2}\right)$. Participants were defined into four classes based on BMI: underweight $\left(\mathrm{BMI}<18.5 \mathrm{~kg} / \mathrm{m}^{2}\right)$, normal $\left(18.5 \leq \mathrm{BMI}<23.0 \mathrm{~kg} / \mathrm{m}^{2}\right)$, overweight $\left(23.0 \leq \mathrm{BMl}<25.0 \mathrm{~kg} / \mathrm{m}^{2}\right)$, and obesity (BMI $\geq 25.0 \mathrm{~kg} /$ $\mathrm{m}^{2}$ ), according to the World Health Organization classification of BMI in adult Asians [23]. Systolic blood pressure (SBP) and diastolic blood pressure (DBP) were measured twice in the 
right arm using a standardized mercury or automatic sphygmomanometer depending on the institution. Participants were seated for at least five minutes before the blood pressure measurements, and the mean of the two blood pressure readings was recorded for data analysis. Laboratory evaluations were performed using blood samples obtained after participants had fasted overnight. Blood concentrations of glucose, total cholesterol, high-density lipoprotein (HDL) cholesterol, and triglycerides were measured using the enzyme method (ADVIA 1650 and ADVIA 1800; Siemens Healthineers, Deerfield, IL, USA). Low-density lipoprotein (LDL) cholesterol levels were calculated using the Friedewald formula [24] in individuals with blood triglyceride levels $<4.52 \mathrm{mmol} / \mathrm{L}$. CRP was measured using a turbidimetric immunoassay (ADVIA 1650 and ADVIA 1800; Siemens Healthineers). Hypertension was considered to be present when the SBP was at least 140 $\mathrm{mmHg}$, the DBP was at least $90 \mathrm{mmHg}$, or if hypertension was self-reported based on a physician's diagnosis. Diabetes was defined as a fasting blood glucose level $\geq 7.0 \mathrm{mmol} / \mathrm{L}$, or a self-reported physician's diagnosis. Dyslipidemia was defined based on a total cholesterol level $\geq 5.957 \mathrm{mmol} / \mathrm{L}$, an LDL cholesterol level $\geq 3.885 \mathrm{mmol} / \mathrm{L}$, an $\mathrm{HDL}$ cholesterol level $<1.036 \mathrm{mmol} / \mathrm{L}$, a triglyceride level $\geq 2.260 \mathrm{mmol} / \mathrm{L}$, or a selfreported physician's diagnosis. Other diseases, such as stroke, angina, and myocardial infarction, were defined only based on a self-reported physician's diagnosis.

The outcome of our study was mortality. To verify participants' vital status, their records in our study were crosschecked with death statistics from the National Statistical Office via the Korea Centers for Disease Control and Prevention using an anonymized form through December 2013. Cardiovascular mortality was evaluated according to the International Classification of Diseases, 10th revision. Deaths caused by diseases in the circulatory system (100-199) were considered to be cardiovascular deaths. As the follow-up period, we used the period between the month in which each participant first participated in the study and the month of death, or December 2013 for surviving participants.

\section{Statistical Analysis}

Gender-stratified analyses were performed. Blood CRP concentrations were classified into the following three groups, according to the National Academy of Clinical Biochemistry Laboratory Medicine Practice Guidelines (NACB LMPG): low (CRP $<1.0 \mathrm{mg} / \mathrm{L})$, intermediate $(1.0 \leq \mathrm{CRP} \leq 3.0 \mathrm{mg} / \mathrm{L})$, and high
(CRP $>3.0 \mathrm{mg} / \mathrm{L}$ ) [5]. To identify category-free associations, blood CRP concentrations were also analyzed as a continuous variable. Continuous variables are represented by mean and standard deviation (SD), or median and interquartile range for skewed variables (skewness $>|2|$ ). Categorical variables are represented as number and percentage. We used the $t$-test, analysis of variance, the Mann-Whitney test, the Kruskal-Wallis test, and the chi-square test for comparisons. We estimated hazard ratios (HRs) and 95\% confidence intervals (Cls) between CRP and mortality using the Cox proportional hazard model. The proportional hazard assumption was assessed by including interactions with time as time-dependent covariates in our model, and no obvious violations were found ( $p$ for proportional test $>0.05$ ). As adjustment variables, we selected age, rural region, BMI, educational status, alcohol use, smoking status, regular exercise, the presence of disease (hypertension, diabetes, and dyslipidemia), SBP, DBP, and fasting concentrations of blood glucose, total cholesterol, triglycerides, and HDL cholesterol. Adjustment variables were selected based on previous studies $[11,13,17]$. We employed restricted cubic splines (RCSs) to evaluate the possibility of complex (i.e., non-linear) hazard functions [25]. In this method, we selected five CRP concentration values as knots based on CRP concentration percentiles, tested the linear and non-linear associations between knots using a cubic function, and presented the integrated graph smoothly. Since the RCS could be affected by outliers, we excluded values lower than the 1st percentile and greater than the 99th percentile. An interaction term was created between hypertension status and CRP and was added into the Cox proportional hazard model. Sensitivity analysis was performed by excluding deaths that occurred within two years from the month that each participant first participated in the study in order to rule out deaths caused by unknown underlying diseases. Since blood CRP concentrations were right-skewed, another sensitivity analysis was performed using log-transformed blood CRP concentrations. All statistical analyses were performed using SAS version 9.3 (SAS Institute Inc., Cary, NC, USA), and RCS analysis was carried out using the SAS LGTPHCURV9 macro [26]. The $p$-values $<0.05$ were defined as indicating statistical significance.

\section{RESULTS}

Table 1 shows the baseline characteristics of the study participants. The overall mean age was 58.9 years (SD, 9.1 years), 
Table 1. Baseline characteristics of participants by C-reactive protein category by gender

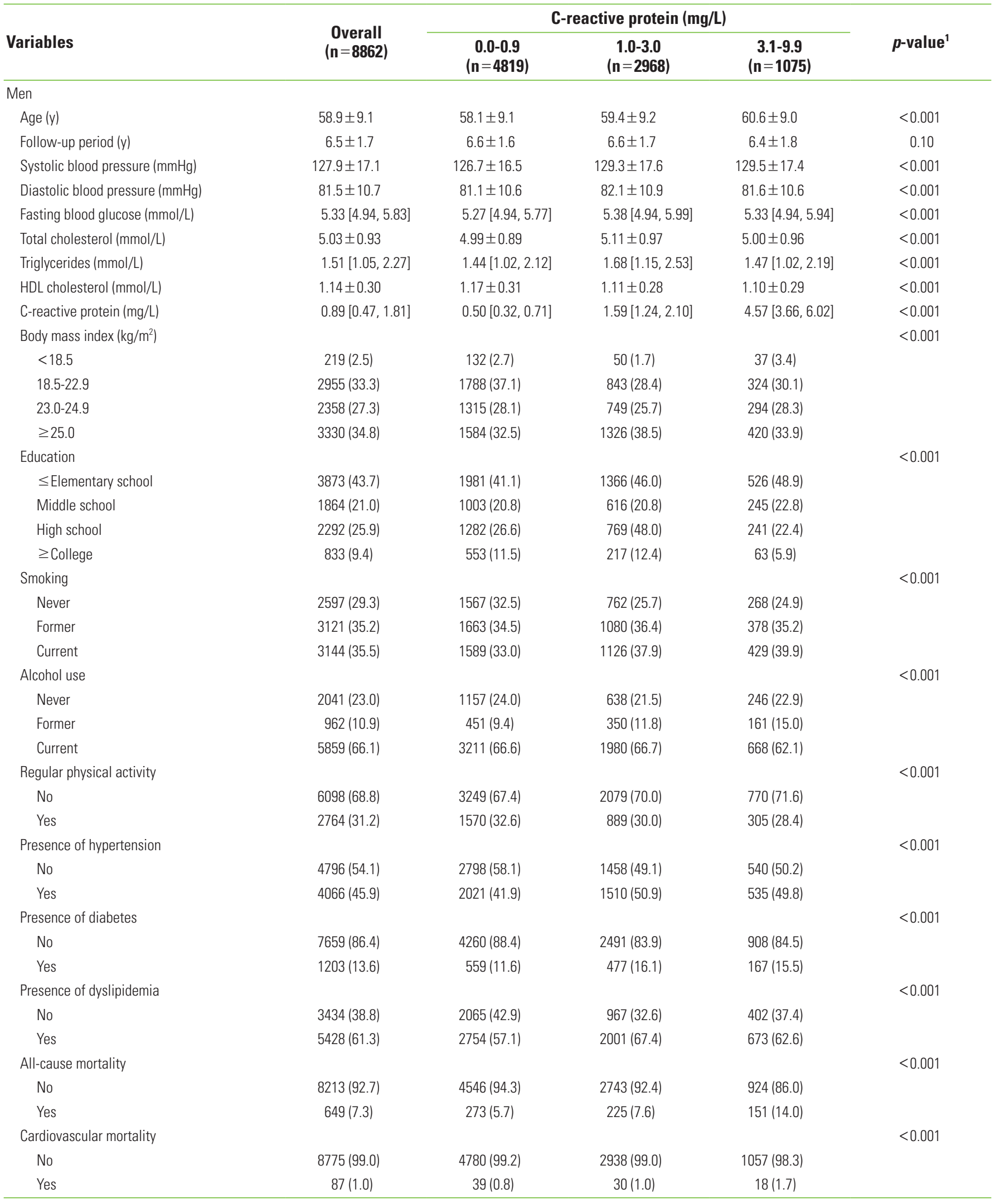


Table 1. Continued from the previous page

\begin{tabular}{|c|c|c|c|c|c|}
\hline \multirow[b]{2}{*}{ Variables } & \multirow{2}{*}{$\begin{array}{c}\text { Overall } \\
(n=14371)\end{array}$} & \multicolumn{3}{|c|}{ C-reactive protein (mg/L) } & \multirow[b]{2}{*}{$p$-value } \\
\hline & & $\begin{array}{c}0.0-0.9 \\
(n=9221)\end{array}$ & $\begin{array}{c}1.0-3.0 \\
(n=3858)\end{array}$ & $\begin{array}{c}3.1-9.9 \\
(n=1292)\end{array}$ & \\
\hline \multicolumn{6}{|l|}{ Women } \\
\hline Age (y) & $57.8 \pm 9.4$ & $56.8 \pm 9.5$ & $59.3 \pm 9.0$ & $59.6 \pm 9.1$ & $<0.001$ \\
\hline Follow-up period (y) & $6.6 \pm 1.5$ & $6.6 \pm 1.5$ & $6.6 \pm 1.6$ & $6.7 \pm 1.5$ & 0.03 \\
\hline Systolic blood pressure (mmHg) & $125.2 \pm 18.2$ & $123.7 \pm 18.0$ & $127.6 \pm 18.2$ & $128.5 \pm 18.5$ & $<0.001$ \\
\hline Diastolic blood pressure (mmHg) & $78.4 \pm 11.1$ & $77.7 \pm 11.0$ & $79.5 \pm 11.2$ & $80.2 \pm 11.2$ & $<0.001$ \\
\hline Fasting glucose (mmol/L) & $5.11[4.77,5.55]$ & $5.05[4.72,5.44]$ & $5.22[4.83,5.72]$ & $5.22[4.83,5.77]$ & $<0.001$ \\
\hline Total cholesterol (mmol/L) & $5.30 \pm 0.96$ & $5.23 \pm 0.93$ & $5.40 \pm 0.99$ & $5.47 \pm 1.03$ & $<0.001$ \\
\hline Triglycerides (mmol/L) & $1.36[0.97,1.93]$ & $1.27[0.93,1.77]$ & $1.53[1.08,2.18]$ & $1.50[1.07,2.18]$ & $<0.001$ \\
\hline HDL cholesterol (mmol/L) & $1.20 \pm 0.28$ & $1.23 \pm 0.28$ & $1.16 \pm 0.26$ & $1.14 \pm 0.27$ & $<0.001$ \\
\hline C-reactive protein (mg/L) & $0.68[0.36,1.39]$ & $0.44[0.27,0.65]$ & $1.52[1.22,2.03]$ & $4.52[3.59,6.10]$ & $<0.001$ \\
\hline Body mass index $\left(\mathrm{kg} / \mathrm{m}^{2}\right)$ & & & & & $<0.001$ \\
\hline$<18.5$ & $243(1.7)$ & $195(2.1)$ & $34(0.9)$ & $14(1.1)$ & \\
\hline $18.5-22.9$ & $4473(31.1)$ & $3380(36.7)$ & $847(22.0)$ & $246(19.0)$ & \\
\hline $23.0-24.9$ & $3680(26.0)$ & $2505(27.8)$ & $901(23.6)$ & $274(21.4)$ & \\
\hline$\geq 25.0$ & $5975(31.2)$ & $3141(27.5)$ & $2076(36.0)$ & $758(38.5)$ & \\
\hline Education & & & & & $<0.001$ \\
\hline$\leq$ Elementary school & $9504(66.1)$ & 5787 (62.8) & $2782(72.1)$ & $935(72.4)$ & \\
\hline Middle school & $2183(15.2)$ & $1478(16.0)$ & $529(13.7)$ & $176(13.6)$ & \\
\hline High school & 2199 (15.3) & $1586(17.2)$ & $461(11.9)$ & $152(11.8)$ & \\
\hline$\geq$ College & $485(3.4)$ & $370(4.0)$ & $86(2.2)$ & $29(2.2)$ & \\
\hline Smoking & & & & & $<0.001$ \\
\hline Never & $13849(96.4)$ & 8937 (96.9) & 3679 (95.4) & $1233(95.4)$ & \\
\hline Former & $171(1.2)$ & $85(0.9)$ & $64(1.7)$ & $22(1.7)$ & \\
\hline Current & $351(2.4)$ & $199(2.2)$ & $115(3.0)$ & $37(2.9)$ & \\
\hline Alcohol use & & & & & 0.003 \\
\hline Never & 9824 (68.4) & $6251(67.8)$ & $2650(68.7)$ & $923(71.4)$ & \\
\hline Former & $495(3.4)$ & $296(3.2)$ & $145(3.8)$ & $54(4.2)$ & \\
\hline Current & $4052(28.2)$ & $2674(29.0)$ & $1063(27.6)$ & $315(24.4)$ & \\
\hline Regular physical activity & & & & & 0.02 \\
\hline No & $9925(69.1)$ & $6320(68.5)$ & 2669 (69.2) & $936(72.4)$ & \\
\hline Yes & $4446(30.9)$ & $2901(31.5)$ & 1189 (30.8) & $356(27.6)$ & \\
\hline Presence of hypertension & & & & & $<0.001$ \\
\hline No & 8321 (57.9) & $5783(62.7)$ & $1902(49.3)$ & $636(49.2)$ & \\
\hline Yes & $6050(42.1)$ & 3438 (37.3) & $1956(50.7)$ & $656(50.8)$ & \\
\hline Presence of diabetes & & & & & $<0.001$ \\
\hline No & $12975(90.3)$ & $8574(93.0)$ & $3296(85.4)$ & 1105 (85.5) & \\
\hline Yes & $1396(9.7)$ & $647(7.0)$ & $562(14.6)$ & $187(14.5)$ & \\
\hline Presence of dyslipidemia & & & & & $<0.001$ \\
\hline No & $6148(42.8)$ & 4412 (47.8) & 1339 (34.7) & $397(30.7)$ & \\
\hline Yes & $8223(57.2)$ & $4809(52.2)$ & 2519 (65.3) & 895 (69.3) & \\
\hline All-cause mortality & & & & & $<0.001$ \\
\hline No & 14004 (97.4) & 9032 (98.0) & 3731 (96.7) & $1241(96.1)$ & \\
\hline Yes & $367(2.6)$ & $189(2.0)$ & 127 (3.3) & 51 (3.9) & \\
\hline Cardiovascular mortality & & & & & $<0.001$ \\
\hline No & $14293(99.5)$ & 9181 (99.6) & 3831 (99.3) & $1281(99.1)$ & \\
\hline Yes & $78(0.5)$ & $40(0.4)$ & $27(0.7)$ & $11(0.9)$ & \\
\hline
\end{tabular}

Values are presented as number $(\%)$, mean $\pm S D$, or median [IQR].

$H D L$, high-density lipoprotein; SD, standard deviation; IQR, interquartile range

${ }^{1} p$-values were derived from analysis of variance, the Kruskal-Wallis test, or the chi-square test. 
and the mean duration of follow-up was 6.5 years (SD, 1.7 years) for men. The overall mean age was 57.8 years (SD, 9.4 years), and the mean duration of follow-up was 6.6 years (SD, 1.5 years) for women. Most variables showed significant differences in their values among the CRP concentration groups. Overall, men participants had a higher median CRP concentration than women participants $(0.89 \mathrm{mg} / \mathrm{L}$ for men, $0.68 \mathrm{mg} / \mathrm{L}$ for women). In order to evaluate selection bias, we compared the baseline characteristics between study participants and non-participants, and did not find a statistically significant difference in CRP concentration (Supplemental Table 1).

Table 2 shows the result of the Cox regression analysis of CRP on all-cause and cardiovascular mortality per 1000 person-years. The high-CRP group showed the highest mortality rate. During the follow-up period, 649 men participants and 367 women participants died. Adjusting for our adjustment variables attenuated the strength of the association. Compared to the low-CRP group, the high-CRP group showed a significant adjusted HR for both gender: the HR was 1.98 (95\% $\mathrm{Cl}, 1.61$ to 2.42$)$ for men and $1.41(95 \% \mathrm{Cl}, 1.03$ to 1.95$)$ for women, while the intermediate-CRP group showed a significant adjusted HR only for women: the $\mathrm{HR}$ was $1.17(95 \% \mathrm{Cl}$, 0.98 to 1.40$)$ for men and $1.27(95 \% \mathrm{Cl}, 1.01$ to 1.61$)$ for women. The results of the Cox regression analysis of CRP levels on cardiovascular mortality were similar to those between CRP levels and all-cause mortality, although the relationship was only significant for continuous CRP concentrations in men. In the sensitivity analysis, in which deaths occurring within two years from the beginning of study participation were excluded, the HR was attenuated, but the tendency was consistent. When blood CRP concentrations were used as a continuous variable, the adjusted HR for CRP and all-cause mortality for men was $1.10(95 \% \mathrm{Cl}, 1.05$ to 1.14$)$ and $1.05(95 \% \mathrm{Cl}, 0.98$ to 1.12) for women. When analyses were performed using logtransformed CRP values, the HR likewise showed a consistent tendency. The adjusted HR between CRP and all-cause mortality for men was $1.26(95 \% \mathrm{Cl}, 1.16$ to 1.36$)$ and $1.16(95 \% \mathrm{Cl}$, 1.04 to 1.29 ) for women. The sensitivity analysis between CRP and cardiovascular mortality showed a consistent tendency (data not shown).

Table 2. Cox regression analysis of C-reactive protein on all-cause and cardiovascular mortality

\begin{tabular}{|c|c|c|c|c|c|c|}
\hline C-reactive protein (mg/L) & $\mathbf{n}$ & No. of deaths & $\begin{array}{c}\text { Mortality per } 1000 \\
\text { person-years }\end{array}$ & Unadjusted & Age-adjusted & Multi-adjusted' \\
\hline \multicolumn{7}{|l|}{ All-cause mortality } \\
\hline \multicolumn{7}{|l|}{ Men } \\
\hline $\operatorname{Low}(0.0-0.9)$ & 4819 & 273 & 8.6 & 1.00 (reference) & 1.00 (reference) & 1.00 (reference) \\
\hline Intermediate (1.0-3.0) & 2968 & 225 & 11.6 & $1.34(1.12,1.60)$ & $1.19(1.00,1.42)$ & $1.17(0.98,1.40)$ \\
\hline High (3.1-9.9) & 1075 & 151 & 21.8 & $2.53(2.07,3.08)$ & $2.07(1.70,2.53)$ & $1.98(1.61,2.42)$ \\
\hline \multicolumn{7}{|l|}{ Women } \\
\hline Low (0.0-0.9) & 9221 & 189 & 3.1 & 1.00 (reference) & 1.00 (reference) & 1.00 (reference) \\
\hline Intermediate (1.0-3.0) & 3858 & 127 & 5.0 & $1.60(1.28,2.00)$ & $1.31(1.05,1.65)$ & $1.27(1.01,1.61)$ \\
\hline High (3.1-9.9) & 1292 & 51 & 5.9 & $1.88(1.38,2.56)$ & $1.46(1.07,1.99)$ & $1.41(1.03,1.95)$ \\
\hline Continuous (per 1.0 mg/L) & 14371 & 367 & 3.9 & $1.13(1.07,1.19)$ & $1.07(1.10,1.14)$ & $1.06(1.00,1.13)$ \\
\hline High (3.1-9.9) & 1075 & 18 & 2.6 & $2.11(1.21,3.68)$ & $1.74(0.99,3.04)$ & $1.64(0.92,2.91)$ \\
\hline Continuous (per 1.0 mg/L) & 8862 & 87 & 1.5 & $1.19(1.08,1.31)$ & $1.15(1.04,1.26)$ & $1.14(1.03,1.26)$ \\
\hline \multicolumn{7}{|l|}{ Women } \\
\hline $\operatorname{Low}(0.0-0.9)$ & 9221 & 40 & 0.7 & 1.00 (reference) & 1.00 (reference) & 1.00 (reference) \\
\hline Intermediate (1.0-3.0) & 3858 & 27 & 1.1 & $1.60(0.98,2.60)$ & $1.27(0.78,2.07)$ & $1.32(0.80,2.19)$ \\
\hline High (3.1-9.9) & 1292 & 11 & 1.3 & $1.80(0.97,3.70)$ & $1.38(0.71,2.69)$ & $1.53(0.76,3.06)$ \\
\hline Continuous (per 1.0 mg/L) & 14371 & 78 & 0.8 & $1.16(1.04,1.29)$ & $1.09(0.97,1.22)$ & $1.11(0.98,1.25)$ \\
\hline
\end{tabular}

Values are presented as hazard ratio (95\% confidence interval).

${ }^{1}$ Adjusted for age, rural region, body mass index, educational status, alcohol use, smoking status, regular exercise, presence of disease (hypertension, diabetes, and dyslipidemia), systolic blood pressure, diastolic blood pressure, fasting blood glucose, and concentrations of total cholesterol, triglycerides, and high-density lipoprotein cholesterol. 
In Figure 1, the RCS shows a significant non-linear pattern between blood CRP concentrations and all-cause mortality for men ( $p$-value for the non-linear relation of $0.048 ; p$-value for the linear relation lower than 0.001$)$, while a significant linear pattern was found for women ( $p$-value for the non-linear relation of $0.267 ; p$-value for the linear relation of 0.013 ). The RCS between blood CRP concentrations and cardiovascular mortality did not show a significant association. Table 3 shows the

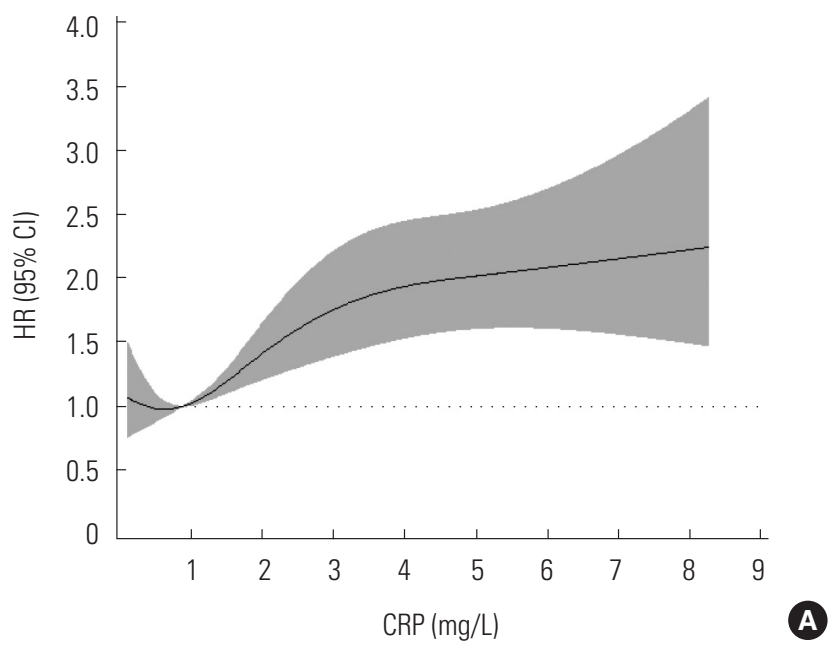

All-cause mortality, among men

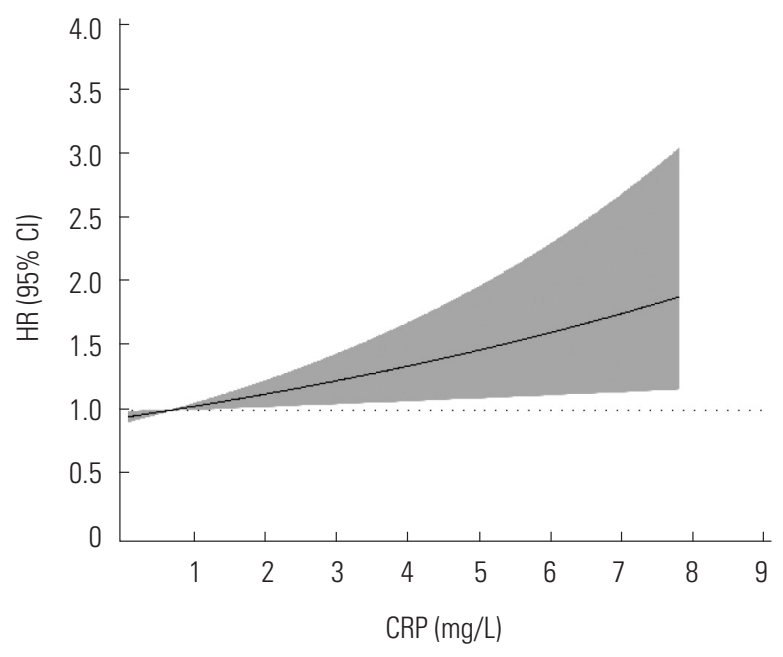

interaction of hypertension with this relationship in both gender. All interaction terms were insignificant. When CRP was analyzed as a categorical variable (Supplemental Table 2), only the interaction term between CRP and hypertension for allcause mortality was significant in a comparison of the lowCRP and high-CRP groups in women.

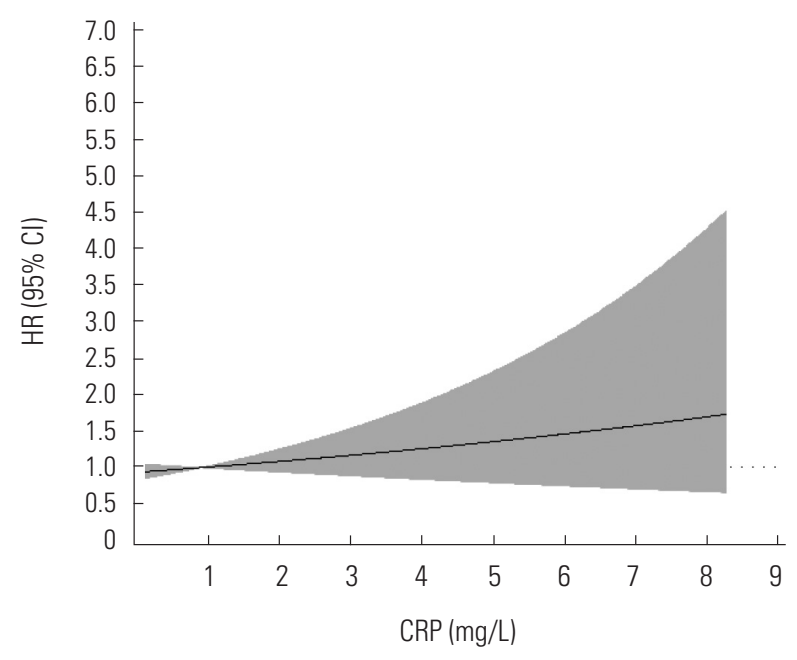

Cardiovascular mortality, among men

B

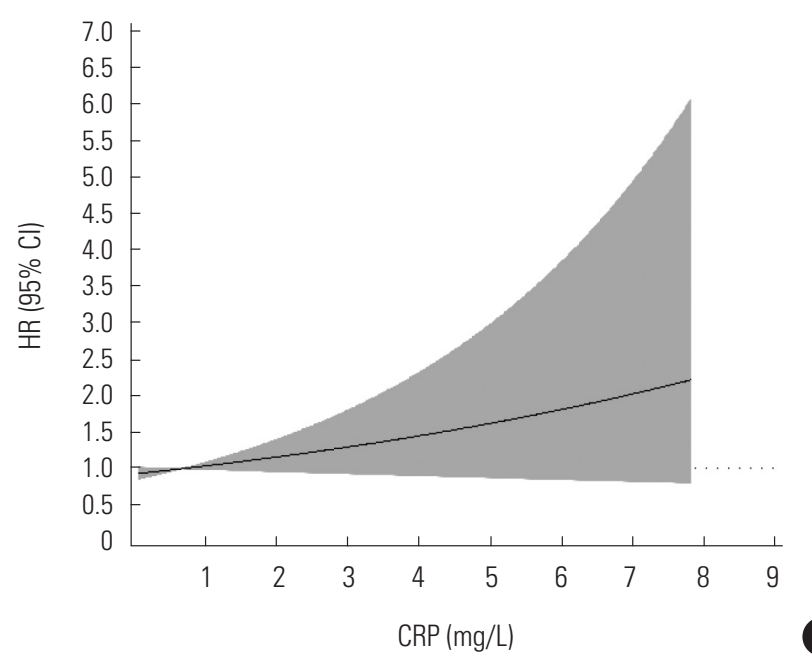

All-cause mortality, among women

Cardiovascular mortality, among women

(D)

Figure 1. The associations of CRP concentrations with HRs for all-cause mortality $(A, C)$ and cardiovascular mortality (B, D). Knots were set at the 5th, 25th, 75th, and 95th percentiles, and the plot was truncated at the 1st and 99th percentiles. The median CRP level was used as the reference. HRs were adjusted for age, rural region, body mass index, educational status, alcohol use, smoking status, regular exercise, the presence of disease (hypertension, diabetes, and dyslipidemia), systolic blood pressure, diastolic blood pressure, fasting blood glucose, and concentrations of total cholesterol, triglycerides, and high-density lipoprotein cholesterol. In (A), the $p$-value for the non-linear relation was 0.048 , so we show the spline model. In (C), the $p$-value for the non-linear relation was 0.267 , but the $p$-value for the linear relation was 0.013 , so we show the linear model. In (B) and (D), neither the linear nor the non-linear relation was significant (all $p$-values $>0.05$ ). In these cases, we show the linear model. CRP, C-reactive protein; $\mathrm{HR}$, harzard ratio; $\mathrm{Cl}$, confidence interval. 
Table 3. Cox regression analysis of CRP on all-cause and cardiovascular mortality according to the presence of hypertension

\begin{tabular}{|c|c|c|c|c|c|c|}
\hline CRP (mg/L) & $\mathbf{n}$ & Median CRP (mg/L) & No, of of death & $\begin{array}{c}\text { Mortality per } 1000 \\
\text { person-years }\end{array}$ & $\begin{array}{l}\text { Multi-adjusted } \\
\text { HR (95\% CI) }\end{array}$ & $p$ for interaction \\
\hline \multicolumn{7}{|l|}{ All-cause mortality } \\
\hline \multicolumn{7}{|l|}{ Men } \\
\hline Hypertension ( -) & 4796 & 0.79 & 323 & 10.4 & $1.15(1.09,1.20)$ & - \\
\hline Hypertension (+) & 4066 & 1.01 & 326 & 12.1 & $1.11(1.05,1.17)$ & 0.32 \\
\hline \multicolumn{7}{|l|}{ Women } \\
\hline Hypertension (-) & 8321 & 0.59 & 168 & 3.1 & $1.11(1.02,1.21)$ & - \\
\hline Hypertension (+) & 6050 & 0.84 & 199 & 4.9 & $1.02(0.94,1.11)$ & 0.11 \\
\hline \multicolumn{7}{|l|}{ Cardiovascular mortality } \\
\hline \multicolumn{7}{|l|}{ Men } \\
\hline Hypertension (-) & 4796 & 0.79 & 41 & 1.3 & $1.14(0.98,1.32)$ & - \\
\hline Hypertension (+) & 4066 & 1.01 & 46 & 1.7 & $1.19(1.04,1.37)$ & 0.58 \\
\hline \multicolumn{7}{|l|}{ Women } \\
\hline Hypertension (-) & 8321 & 0.59 & 31 & 0.6 & $1.10(0.88,1.38)$ & - \\
\hline Hypertension (+) & 6050 & 0.84 & 47 & 1.2 & $1.13(0.97,1.31)$ & 0.83 \\
\hline
\end{tabular}

CRP, C-reactive protein; HR, hazard ratio; $\mathrm{Cl}$, confidence interval.

'Adjusted for age, rural region, body mass index, educational status, alcohol use, smoking status, regular exercise, presence of disease (diabetes and dyslipidemia), systolic blood pressure, diastolic blood pressure, fasting blood glucose, and concentrations of total cholesterol, triglycerides, and high-density lipoprotein cholesterol.

\section{DISCUSSION}

We observed a non-linear association between blood CRP concentrations and all-cause mortality in a rural Korean men population, and a linear association in a rural Korean women population. Many observational studies have reported such associations, but most of them analyzed these associations using predetermined CRP risk groups, or based on the $p$-fortrend for fractile-based groups $[12,27,28]$. One meta-analysis showed a log-linear association, but its participants were mostly white [7]. In Figure $1 \mathrm{~A}$ in this study, the HR is shown to have rapidly increased as CRP concentration increased from 1 $\mathrm{mg} / \mathrm{L}$ to $3 \mathrm{mg} / \mathrm{L}$. However, only a small HR increase was found for CRP levels $>3 \mathrm{mg} / \mathrm{L}$. Based on these results, we suggest that a more accurate risk grouping for men in Korea is needed within the intermediate risk group $[20,29]$. Originally, the NACB LMPG risk groups for CRP were determined by US population tertiles, but some studies in East Asia have reported lower average CRP concentrations than those observed in Western countries [30-32]. In contrast, as shown in Figure 1B, only a linear association was found between CRP concentrations and all-cause mortality in women. The estimated HR between CRP and all-cause mortality for women was lower than that for men in our study, although both relationships were significant. This discrepancy may be due to gender differences in CRP concentrations and mortality [12]. In other studies that showed significant associations between CRP and mortality for men, significant associations were rarely found in women $[11,27]$. Due to this gender-based discrepancy, further evaluation will be needed regarding the different association patterns observed between CRP and mortality according to gender. Meanwhile, associations between CRP and cardiovascular mortality were not found to be significant (Figure 1). This finding is not consistent with our results presented in Table 2, in which CRP concentrations were used as a continuous variable. This discrepancy within our study may be due to methodological differences. Since we excluded outliers for the RCS analysis, the results obtained using this method were more attenuated than those presented in Table 2 . Therefore, we were not able to determine whether a significant association was present between CRP and cardiovascular mortality. The life expectancy of Koreans was 78.5 years for mens and 85.1 for womens in 2013 [33]. Considering the average age of our study participants and the duration of follow-up, we most likely did not include enough cases of cardiovascular mortality. In addition, the HR for cardiovascular mortality in women increased after adjustment (Table 2). However, the results were still insignificant, and the adjusted HR was attenuated in comparison with the unadjusted $H R$, so this may not change the interpretation of our results.

Since this was the first study regarding association between CRP and mortality to be performed in Korean rural communi- 
ties, we compared our findings with those of previous studies conducted in rural areas. One such study conducted in Japan reported that participants within the highest tertile of CRP concentrations showed higher all-cause mortality $(\mathrm{HR}=2.26)$ than the lowest-tertile group in men [6]. A study conducted in Finland showed an insignificant association between CRP and all-cause mortality after adjustment for conventional CVD risk factors [34]. Our study results were consistent with those of the study performed in Japan. In addition, we compared our results to those of another large cohort study in Korea [11]. That study reported a significant association between CRP and all-cause mortality in men. However, our results showed higher CRP concentrations and mortality rates. The population of that study included participants who underwent health checkups in urban areas, and the average age of the participants was lower than in our study. This may have affected differences in blood CRP concentrations, but the presence of such an association was consistent across different populations in Korea. Generally, rural inhabitants had a lower socioeconomic status, less access to health services, and lived in more hazardous environments than urban inhabitants [35]. Due to the difficulty of enrolling rural inhabitants, many large studies targeting apparently healthy people have been conducted in urban areas. Our study is unique in that it focused on multiple rural areas, showing the health landscape among a difficult-tostudy population.

Another aim of our study was to evaluate the effect of hypertension in modifying the association between blood CRP concentrations and mortality. However, our analysis that was stratified according to the presence of hypertension did not show a significant interaction ( $p$ for interaction $>0.1$ ), and including hypertension as a confounder in our analyses did not cause the relationship between CRP and all-cause mortality to become insignificant (Table 2). Therefore, hypertension might be neither an effect modifier nor a mediator. Although a significant interaction was found between CRP risk groups and all-cause mortality when CRP concentration was analyzed as a categorical variable (Supplemental Table 2), we were not able to reach a conclusion regarding effect modification due to the low number of deaths over an insufficient follow-up period. Similarly, previous studies evaluating the effect modification of diabetes and hypertension on the relationship between CRP and mortality reported insignificant results $[15,16]$.

This study has some limitations. First, although we recruited participants from 11 rural communities in order to obtain a representative sample, only volunteers participated in the study. Therefore, selection bias may have been present between study participants and non-participants. As a result, our findings must be applied carefully to the entire population of rural Korean inhabitants. Second, we were not able to examine the incidence of some diseases, such as hypertension, diabetes, dyslipidemia, or CVD. Not only disease presence, but disease incidence may affect the association between CRP and mortality. Further research with respect to disease incidence therefore needs to be carried out. Third, a limited approach to disease history was another limitation of our study. We only evaluated the presence of common diseases, such that the effects of other inflammatory diseases that affect CRP, such as rheumatoid arthritis, were not assessed. Fourth, the participants' history of taking medications with direct effects on CRP concentrations was not available in our data. Angiotensin II receptor blockers, beta-blockers, and statins have been reported to reduce CRP concentrations [36,37]. Finally, we measured blood CRP concentrations only once. Repeat measurements would be needed to evaluate intraparticipant CRP variability. However, in a previous study, changes in CRP were not found to have a significant effect on mortality [11].

In conclusion, blood CRP concentration showed a positive association with all-cause mortality and cardiovascular mortality in a rural Korean population. The strength of the association among men was greater than among women. This association was not found to be modified by the presence of hypertension. Further evaluation of the associations between CRP and other outcomes, such as hypertension or CVD incidence, is needed.

\section{ACKNOWLEDGEMENTS}

This work was supported by a research program funded by the Korea Centers for Disease Control and Prevention (funding code 2004-E71004-00, 2005-E71013-00, 2005-E71011-00, 2006-E71002-00, 2006-E71011-00, 2006-E71009-00, 2007E71002-00, 2007-E71013-00, 2008-E71004-00, 2009-E7100600, 2010-E71003-00, 2011-E71002-00).

\section{CONFLICT OF INTEREST}

The authors have no conflicts of interest associated with the material presented in this paper. 


\section{ORCID}

Jung Hyun Lee http://orcid.org/0000-0001-7141-4532

Hyungseon Yeom http://orcid.org/0000-0002-8004-8244

Hyeon Chang Kim http://orcid.org/0000-0001-7867-1240

II Suh http://orcid.org/0000-0002-9689-7849

Bo Youl Choi http://orcid.org/0000-0003-0115-5736

\section{REFERENCES}

1. Libby P. Inflammatory mechanisms: the molecular basis of inflammation and disease. Nutr Rev 2007;65(12 Pt 2):S140-S146.

2. Shacter E, Weitzman SA. Chronic inflammation and cancer. Oncology (Williston Park) 2002;16(2):217-226.

3. Willerson JT, Ridker PM. Inflammation as a cardiovascular risk factor. Circulation 2004;109(21 Suppl 1):I12- II10.

4. Windgassen EB, Funtowicz L, Lunsford TN, Harris LA, Mulvagh SL. C-reactive protein and high-sensitivity C-reactive protein: an update for clinicians. Postgrad Med 2011;123(1):114-119.

5. NACB LMPG Committee Members, Myers GL, Christenson RH, Cushman M, Ballantyne CM, Cooper GR, et al. National Academy of Clinical Biochemistry Laboratory Medicine Practice guidelines: emerging biomarkers for primary prevention of cardiovascular disease. Clin Chem 2009;55(2):378-384.

6. Makita S, Nakamura M, Satoh K, Tanaka F, Onoda T, Kawamura $K$, et al. Serum C-reactive protein levels can be used to predict future ischemic stroke and mortality in Japanese men from the general population. Atherosclerosis 2009;204(1):234-238.

7. Emerging Risk Factors Collaboration, Kaptoge S, Di Angelantonio E, Lowe G, Pepys MB, Thompson SG, et al. C-reactive protein concentration and risk of coronary heart disease, stroke, and mortality: an individual participant meta-analysis. Lancet 2010;375(9709):132-140.

8. Ridker PM. High-sensitivity C-reactive protein as a predictor of all-cause mortality: implications for research and patient care. Clin Chem 2008;54(2):234-237.

9. Ahmadi-Abhari S, Luben RN, Wareham NJ, Khaw KT. Seventeen year risk of all-cause and cause-specific mortality associated with C-reactive protein, fibrinogen and leukocyte count in men and women: the EPIC-Norfolk study. Eur J Epidemiol 2013;28(7):541-550.

10. Goyal A, Terry MB, Jin Z, Siegel AB. C-reactive protein and colorectal cancer mortality in U.S. adults. Cancer Epidemiol Biomarkers Prev 2014;23(8):1609-1618.

11. Sung KC, Ryu S, Chang Y, Byrne CD, Kim SH. C-reactive protein and risk of cardiovascular and all-cause mortality in 268803 East Asians. Eur Heart J 2014;35(27):1809-1816.

12. Doran B, Zhu W, Muennig P. Gender differences in cardiovascular mortality by C-reactive protein level in the United States: evidence from the National Health and Nutrition Examination Survey III. Am Heart J 2013;166(1):45-51.

13. Kim Kl, Oh SW, Ahn S, Heo NJ, Kim S, Chin HJ, et al. CRP level and HDL cholesterol concentration jointly predict mortality in a Korean population. Am J Med 2012;125(8):787- 795.e4.

14. Ding D, Wang M, Su D, Hong C, Li X, Yang Y, et al. Body mass index, high-sensitivity C-reactive protein and mortality in Chinese with coronary artery disease. PLoS One 2015;10(8): e0135713.

15. Sung JW, Lee SH, Byrne CD, Chung PW, Won YS, Sung KC. High-sensitivity C-reactive protein is associated with the presence of coronary artery calcium in subjects with normal blood pressure but not in subjects with hypertension. Arch Med Res 2014;45(2):170-176.

16. Kengne AP, Batty GD, Hamer M, Stamatakis E, Czernichow S. Association of C-reactive protein with cardiovascular disease mortality according to diabetes status: pooled analyses of 25,979 participants from four U.K. prospective cohort studies. Diabetes Care 2012;35(2):396-403.

17. Koenig W, Khuseyinova N, Baumert J, Meisinger C. Prospective study of high-sensitivity C-reactive protein as a determinant of mortality: results from the MONICA/KORA Augsburg Cohort Study, 1984-1998. Clin Chem 2008;54(2):335-342.

18. Yusuf S, Reddy S, Ounpuu S, Anand S. Global burden of cardiovascular diseases. Part II: variations in cardiovascular disease by specific ethnic groups and geographic regions and prevention strategies. Circulation 2001;104(23):2855-2864.

19. Miranda JJ, Gilman RH, Smeeth L. Differences in cardiovascular risk factors in rural, urban and rural-to-urban migrants in Peru. Heart 2011;97(10):787-796.

20. Kelley-Hedgepeth A, Lloyd-Jones DM, Colvin A, Matthews KA, Johnston J, Sowers MR, et al. Ethnic differences in C-reactive protein concentrations. Clin Chem 2008;54(6):1027-1037.

21. Kim Y, Han BG; KoGES group. Cohort profile: the Korean genome and epidemiology study (KoGES) Consortium. Int J Epidemiol 2016. http://dx.doi.org/10.1093/ije/dyv316.

22. Lee EH, Park SK, Ko KP, Cho IS, Chang SH, Shin HR, et al. Cigarette smoking and mortality in the Korean Multi-center Cancer Cohort (KMCC) study. J Prev Med Public Health 2010;43(2): 151-158 (Korean).

23. World Health Organization. The Asia-Pacific perspective: rede- 
fining obesity and its treatment [cited 2016 Sep 4]. Available from: http://www.wpro.who.int/nutrition/documents/docs/ Redefiningobesity.pdf.

24. Friedewald WT, Levy RI, Fredrickson DS. Estimation of the concentration of low-density lipoprotein cholesterol in plasma, without use of the preparative ultracentrifuge. Clin Chem 1972;18(6):499-502.

25. Heinzl H, Kaider A. Gaining more flexibility in Cox proportional hazards regression models with cubic spline functions. Comput Methods Programs Biomed 1997;54(3):201-208.

26. Li R, Hertzmark E, Louie M, Chen L, Spiegelman D. The SAS LGTPHCURV9 macro; 2011 [cited 2016 Sep 4]. Available from: https://cdn1.sph.harvard.edu/wp-content/uploads/sites/271/ 2012/09/lgtphcurv9_7-3-2011.pdf.

27. Iso H, Cui R, Date C, Kikuchi S, Tamakoshi A; JACC Study Group. C-reactive protein levels and risk of mortality from cardiovascular disease in Japanese: the JACC Study. Atherosclerosis 2009;207(1):291-297.

28. Currie CJ, Poole CD, Conway P. Evaluation of the association between the first observation and the longitudinal change in C-reactive protein, and all-cause mortality. Heart 2008;94(4): 457-462.

29. Pearson TA, Mensah GA, Alexander RW, Anderson JL, Cannon RO 3rd, Criqui M, et al. Markers of inflammation and cardiovascular disease: application to clinical and public health practice: a statement for healthcare professionals from the Centers for Disease Control and Prevention and the American Heart Association. Circulation 2003;107(3):499-511.

30. Woloshin S, Schwartz LM. Distribution of C-reactive protein values in the United States. N Engl J Med 2005;352(15):16111613.

31. Saito I, Sato S, Nakamura M, Kokubo Y, Mannami T, Adachi H, et al. A low level of $\mathrm{C}$-reactive protein in Japanese adults and its association with cardiovascular risk factors: the Japan NCVC-Collaborative Inflammation Cohort (JNIC) study. Atherosclerosis 2007;194(1):238-244.

32. Zhao Y, Wang R, Ma X, Yan X, Zhang Z, He X, et al. Distribution of $C$-reactive protein and its association with cardiovascular risk factors in a population-based sample of Chinese. Dis Markers 2010;28(6):333-342.

33. Organization for Economic Cooperation and Development. Health status [cited 2015 Nov 29]. Available from: http://stats. oecd.org/index.aspx?DataSetCode=HEALTH_STAT.

34. Kuoppamäki M, Salminen M, Vahlberg T, Irjala K, Kivelä SL, Räihä I. High sensitive C-reactive protein (hsCRP), cardiovascular events and mortality in the aged: a prospective 9-year follow-up study. Arch Gerontol Geriatr 2015;60(1):112-117.

35. Smith KB, Humphreys JS, Wilson MG. Addressing the health disadvantage of rural populations: how does epidemiological evidence inform rural health policies and research? Aust J Rural Health 2008;16(2):56-66.

36. Hage FG. C-reactive protein and hypertension. J Hum Hypertens 2014;28(7):410-415.

37. Ridker PM, Danielson E, Fonseca FA, Genest J, Gotto AM Jr, Kastelein JJ, et al. Reduction in C-reactive protein and LDL cholesterol and cardiovascular event rates after initiation of rosuvastatin: a prospective study of the JUPITER trial. Lancet 2009;373(9670):1175-1182. 
Supplemental Table 1. Comparison of baseline characteristics between study participants and non-participants

\begin{tabular}{|c|c|c|c|c|c|}
\hline \multirow{2}{*}{ Variables } & \multicolumn{2}{|c|}{ Study participants } & \multicolumn{2}{|c|}{ Non-participants } & \multirow{2}{*}{$p$-value ${ }^{1}$} \\
\hline & $\mathbf{n}$ & Mean \pm SD & $\mathbf{n}$ & Mean \pm SD & \\
\hline \multicolumn{6}{|l|}{ Men } \\
\hline Age (y) & 8862 & $58.9 \pm 9.1$ & 773 & $58.9 \pm 9.2$ & 0.88 \\
\hline Systolic blood pressure (mm Hg) & 8862 & $127.9 \pm 17.1$ & 757 & $126.6 \pm 17.5$ & 0.04 \\
\hline Diastolic blood pressure $(\mathrm{mm} \mathrm{Hg})$ & 8862 & $81.5 \pm 10.7$ & 752 & $80.7 \pm 11.8$ & 0.07 \\
\hline Fasting blood glucose (mmol/L) & 8862 & $5.33 \pm 0.88$ & 768 & $5.33 \pm 0.94$ & 0.60 \\
\hline Total cholesterol (mmol/L) & 8862 & $5.03 \pm 0.93$ & 768 & $4.98 \pm 0.97$ & 0.12 \\
\hline Triglycerides (mmol/L) & 8862 & $1.51 \pm 1.22$ & 767 & $1.41 \pm 1.07$ & 0.02 \\
\hline HDL cholesterol (mmol/L) & 8862 & $1.14 \pm 0.30$ & 767 & $1.12 \pm 0.29$ & 0.14 \\
\hline C-reactive protein (mg/L) & 8862 & $0.89 \pm 1.34$ & 233 & $0.85 \pm 1.02$ & 0.57 \\
\hline \multicolumn{6}{|l|}{ Women } \\
\hline Age (y) & 14371 & $57.8 \pm 9.4$ & 1502 & $56.3 \pm 9.1$ & $<0.001$ \\
\hline Systolic blood pressure (mm Hg) & 14371 & $125.2 \pm 18.2$ & 1476 & $124.3 \pm 18.2$ & 0.07 \\
\hline Diastolic blood pressure $(\mathrm{mm} \mathrm{Hg})$ & 14371 & $78.4 \pm 11.1$ & 1466 & $77.2 \pm 11.2$ & $<0.001$ \\
\hline Fasting blood glucose (mmol/L) & 14371 & $5.11 \pm 0.78$ & 1494 & $5.05 \pm 0.67$ & $<0.001$ \\
\hline Total cholesterol (mmol/L) & 14371 & $5.30 \pm 0.96$ & 1494 & $5.20 \pm 0.95$ & $<0.001$ \\
\hline Triglycerides (mmol/L) & 14371 & $1.36 \pm 0.96$ & 1486 & $1.32 \pm 0.93$ & 0.05 \\
\hline HDL cholesterol (mmol/L) & 14371 & $1.20 \pm 0.29$ & 1493 & $1.20 \pm 0.28$ & 0.43 \\
\hline C-reactive protein (mg/L) & 14371 & $0.68 \pm 1.03$ & 434 & $0.64 \pm 1.03$ & 0.17 \\
\hline
\end{tabular}

Values of the concentrations of fasting glucose, triglycerides, and C-reactive protein are presented as median $\pm I Q R$, while other variables are presented as mean $\pm S D$. HDL, high-density lipoprotein; SD, standard deviation; IQR, interquartile range.

${ }^{1} p$-values were derived from the $t$-test and the Mann-Whitney test. 
Supplemental Table 2. Cox regression analysis of CRP on all-cause and cardiovascular mortality according to the presence of hypertension (by CRP group)

\begin{tabular}{|c|c|c|c|c|c|}
\hline & $\mathbf{n}$ & No. of deaths & $\begin{array}{l}\text { Mortality per } 1000 \\
\text { person-years }\end{array}$ & $\begin{array}{c}\text { Multi-adjusted } \\
\text { HR (95\% CI) }\end{array}$ & $\begin{array}{c}p \text { for interaction } \\
\text { (vs. low-CRP group) }\end{array}$ \\
\hline \multicolumn{6}{|l|}{ All-cause mortality } \\
\hline \multicolumn{6}{|l|}{ Men } \\
\hline \multicolumn{6}{|l|}{ Low-CRP group } \\
\hline No hypertension & 2798 & 138 & 7.6 & 1.00 (reference) & \\
\hline Hypertension & 2021 & 135 & 10.1 & $1.10(0.84,1.44)$ & \\
\hline No hypertension & 1458 & 109 & 11.5 & $1.25(0.97,1.61)$ & \\
\hline Hypertension & 1510 & 116 & 11.6 & $1.20(0.90,1.60)$ & \\
\hline High-CRP group & & & & & 0.23 \\
\hline No hypertension & 540 & 76 & 22.0 & $2.23(1.28,2.96)$ & \\
\hline Hypertension & 535 & 75 & 21.7 & $1.92(1.40,2.63)$ & \\
\hline Intermediate-CRP group & & & & & 0.41 \\
\hline No hypertension & 1902 & 45 & 3.6 & $1.12(0.78,1.61)$ & \\
\hline Hypertension & 1956 & 82 & 6.3 & $1.42(1.00,2.01)$ & \\
\hline High-CRP group & & & & & 0.02 \\
\hline No hypertension & 636 & 29 & 6.9 & $2.06(1.35,3.15)$ & \\
\hline Hypertension & 656 & 22 & 4.9 & $1.02(0.61,1.71)$ & \\
\hline \multicolumn{6}{|l|}{ Cardiovascular mortality } \\
\hline \multicolumn{6}{|l|}{ Men } \\
\hline \multicolumn{6}{|l|}{ Low-CRP group } \\
\hline Hypertension & 535 & 11 & 3.2 & $1.15(0.50,2.64)$ & \\
\hline \multicolumn{6}{|l|}{ Women } \\
\hline \multicolumn{6}{|l|}{ Low-CRP group } \\
\hline No hypertension & 5783 & 19 & 0.5 & 1.00 (reference) & \\
\hline Hypertension & 3438 & 21 & 0.9 & $0.78(0.37,1.62)$ & \\
\hline Intermediate-CRP group & & & & & 0.34 \\
\hline No hypertension & 1902 & 8 & 0.6 & $0.96(0.42,2.22)$ & \\
\hline Hypertension & 1956 & 19 & 1.5 & $1.24(0.58,2.66)$ & \\
\hline High-CRP group & & & & & 0.93 \\
\hline No hypertension & 636 & 4 & 1.0 & $1.50(0.50,4.49)$ & \\
\hline Hypertension & 656 & 7 & 1.6 & $1.23(0.46,3.31)$ & \\
\hline
\end{tabular}

CRP, C-reactive protein; HR, hazard ratio; $\mathrm{Cl}$, confidence interval.

'Adjusted for age, rural region, body mass index, educational status, alcohol use, smoking status, regular exercise, the presence of disease (diabetes and dyslipidemia), systolic blood pressure, diastolic blood pressure, fasting blood glucose, and concentrations of total cholesterol, triglycerides, and high-density lipoprotein cholesterol. 